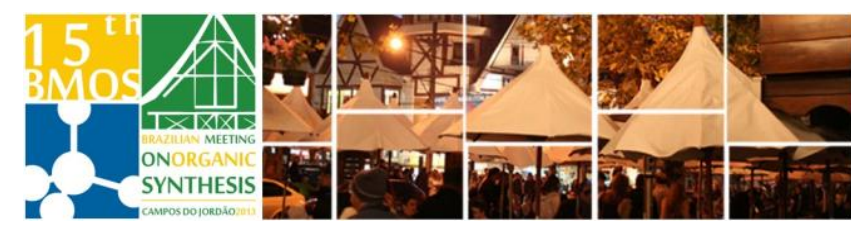

\title{
Enzymatic Kinetic Resolution of Hydroxy Furan and Tiophene 2-substituted
}

\author{
Pires, D. S. F. (PG) ${ }^{\text {**}}$; Ferreira, J. G. (PG) ${ }^{\mathbf{1}}$; Filho, E. F. S. (PG) ${ }^{\mathbf{1}}$; Princival J. L. (PQ) ${ }^{\mathbf{1}}$ \\ 'Departamento de Química Fundamental, Universidade Federal de Pernambuco (UFPE), 50739-901, Recife (PE), Brasil. \\ *dartagnan_pires@hotmail.com
}

Keywords: Enzymatic Kinetic Resolution (EKR), Enantiomeric Excess (e.e.), Enzymes.

\section{INTRODUCTION}

Chiral non racemic secondary alcohols containing 2Furan and Tiophene rings are widely widespread compounds in the environment and they also play important role in biochemical process. ${ }^{1}$ In addition these compounds can be employed as building blocks in the synthesis of bioactive molecules. However, environmentally harmful reagents and many reaction steps are generally assigned to synthetic methodologies that employ it. ${ }^{2}$ Here, we propose a chemoenzymatic methodology to prepare enantioenriched secondary alcohols containing furan and tiophene heterocyclic group.

\section{RESULTS AND DISCUSSION}

Initially a set of sec-alcohols containing furan and tiophene rings 1a-h (Figure 1) were prepared according with the literature ${ }^{3}$ in good yields.

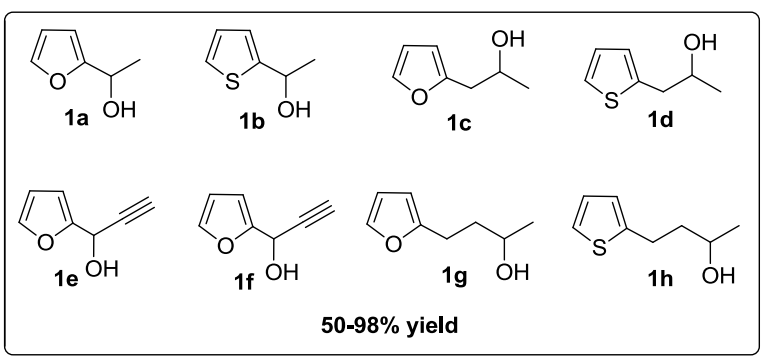

Figure 1. Furan and tiophene derivatives

The racemic compound $\mathbf{1} \mathbf{b}$ was submitted to the enzymatic kinetic resolution (EKR) using vinyl acetate as acyl donor, the enzyme Candida antarctica lipase (CAL-B) and $n$-hexane as a nonpolar organic solvent (Scheme 1).

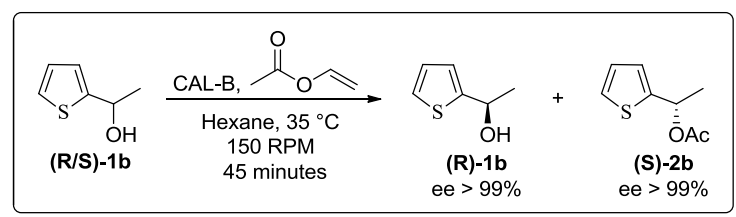

Scheme 1. Analytical scale EKR of (R,S)-1b

The bioresolution of racemic substrate by CAL-B showed an anti Kaslauskas rule preference obtaining the free alcohol (R)-1b and ester (S)-2b in its enantiomeric pure form (e.e. > 99\%).
With this, the initial parameters were extended to EKR of the alcohols 1a-h (Scheme 2 and Table 1).

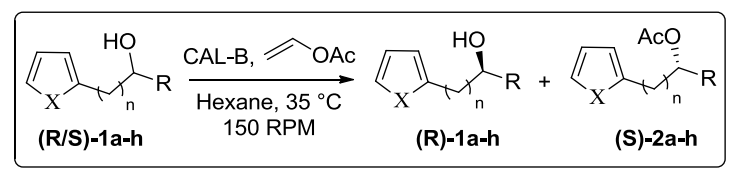

Scheme 2. Racemic alcohols 1a-h EKR.

Table 1. EKR of the racemic alcohols 1a-h.

\begin{tabular}{|c|c|c|c|c|c|c|c|c|c|}
\hline Entry & Substrate & R & $\mathrm{n}$ & $\mathrm{x}$ & $\begin{array}{l}\text { Time } \\
\text { (min) }\end{array}$ & $\begin{array}{l}\text { (R)-la-h } \\
(e . e-\%)\end{array}$ & Yield $^{3}(\%)$ & $\begin{array}{l}\text { (S)-2a-h } \\
(e . e-\%)\end{array}$ & $\begin{array}{c}\text { Yield }^{b} \\
(\%)\end{array}$ \\
\hline 1 & $(\mathrm{R} / \mathrm{S})-\mathbf{2} \mathbf{a}$ & $-\mathrm{CH}_{3}$ & 0 & 0 & 60 & $>99$ & 35 & 79 & 40 \\
\hline 2 & $(\mathrm{R} / \mathrm{S})-\mathbf{2 b}$ & $-\mathrm{CH}_{3}$ & 0 & S & 45 & $>99$ & 49 & $>99$ & 40 \\
\hline 3 & $(\mathrm{R} / \mathrm{S})-2 \mathrm{c}$ & $-\mathrm{CH}_{3}$ & 1 & 0 & 300 & $>99$ & 49 & 80 & 49 \\
\hline 4 & $(\mathrm{R} / \mathrm{S})-2 \mathrm{~d}$ & $-\mathrm{CH}_{3}$ & 1 & $\mathrm{~S}$ & 270 & $>99$ & 46 & $>99$ & 45 \\
\hline 5 & $(\mathrm{R} / \mathrm{S})-2 \mathrm{e}$ & $-\mathrm{CCH}$ & 0 & 0 & 30 & $>99$ & 49 & $>99$ & 30 \\
\hline 6 & $(\mathrm{R} / \mathrm{S})-\mathbf{2 f}$ & $-\mathrm{CCH}$ & 0 & $\mathrm{~S}$ & 120 & 99 & 49 & 68 & 46 \\
\hline 7 & $(\mathbb{R} / S)-2 g$ & $-\mathrm{CH}_{3}$ & 2 & 0 & 10 & $>99$ & 45 & 96 & 49 \\
\hline 8 & $(\mathrm{R} / \mathrm{S})-2 \mathrm{~h}$ & $-\mathrm{CH}_{3}$ & 2 & $\mathrm{~S}$ & 10 & $>99$ & 48 & $>99$ & 39 \\
\hline
\end{tabular}

Isolated vield of the esters (S)-la-h

As can be seen in the table 1, the chiral non racemic $(\boldsymbol{S})$-substrates and $(\boldsymbol{R})$-esters were obtained in an excellent enantioselectivity. Actually the enantiopure compound (S)-1g has been employed as key intermediate in the enantioselective synthesis of bioactive Pyrenophorine. ${ }^{4}$

\section{CONCLUSION}

The alcohols (R)-1a-h and esters (S)-2a-h have been acquired in high (>99\%) and moderated (from $68 \%$ to $99 \%$ ) enantiomeric excess, respectively. The preliminary results have shown that alcohols containing furan and tiophene as heterocyclic compounds could be resolved by CAL-B.

\section{ACKNOWLEDGEMENTS}

CNPq; FACEPE; INCT-INAMI.

\section{REFERENCES}

${ }^{1}$ Lisa, A. P.; Chem. Res. Toxicol. 2013, 26, 6.

${ }^{2}$ Kobayashi, Y. et. al. J. Org. Chem. 1998, 63, 7505.

${ }^{3}$ (a)Wang, L. et. al. Can. J. Chem. 2002, 80, 728; (b)Hashmi, A. et. al.

Tetrahedron. 2009, 65, 9021; (c)Hochsteinan, F. A; et. al.. J. Am. Chem.

Soc., 1948, 70, 3484; (d)Li, X. et.al. J. Org. Chem. 2010, 75, 2981.

${ }^{4}$ Nozoe, S. et. al.. Tetrahedron Lett. 1965, 4675. 